\title{
Prevalence and Associated Factors of Teenage Pregnancy among Secondary and High School Students in the Tiko Health District, South West Region, Cameroon
}

\author{
Ebanja Silva Elonge Gabriel ${ }^{1 *}$, Gregory Edie Halle-Ekane ${ }^{1}$, Mohamed Isah ${ }^{2,3,4}$, \\ Frankline Sevidzem Wirsiy², Max Langmia Nambeke Lebaga', Ndzeshang Dympna Siysila5, \\ Catherine Binye Musi' ${ }^{6}$ Ngong Clovis Chia ${ }^{7}$, Mbome Njie Victor ${ }^{1}$
}

\footnotetext{
${ }^{1}$ Department of Medicine, Faculty of Health Sciences, University of Buea, Buea, Cameroon

${ }^{2}$ Department of Public Health and Hygiene, Faculty of Health Sciences, University of Buea, Buea, Cameroon

${ }^{3}$ Health Organisation Welfare, Yaounde, Cameroon

${ }^{4}$ STEM Higher Institute of Health and Business, Douala, Cameroon

${ }^{5}$ School of Tropical Medicine and Global Health, Nagasaki University, Nagasaki, Japan

${ }^{6}$ Department of Obstetrics and Gynecology, Limbe Regional Hospital, Limbe, Cameroon

${ }^{7}$ Deprtment of Medical Laboratory Science, Faculty of Health Sciences, University of Buea, Buea, Cameroon

Email: *elongaterre@gmail.com, mohamedisahmi@gmail.com,maxlebaga@yahoo.co.uk,ndzeshang@gmail.com,

Kbinye43@gmail.com
}

How to cite this paper: Gabriel, E.S.E., Halle-Ekane, G.E., Isah, M., Wirsiy, F.S., Lebaga, M.L.N., Siysila, N.D., Musi, C.B., Chia, N.C. and Victor, M.N. (2020) Prevalence and Associated Factors of Teenage Pregnancy among Secondary and High School Students in the Tiko Health District, South West Region, Cameroon. Journal of Biosciences and Medicines, 8, 99-113. https://doi.org/10.4236/jbm.2020.89008

Received: June 28, 2020

Accepted: September 11, 2020

Published: September 14, 2020

Copyright $\odot 2020$ by author(s) and Scientific Research Publishing Inc. This work is licensed under the Creative Commons Attribution International License (CC BY 4.0).

http://creativecommons.org/licenses/by/4.0/

(c) (i) Open Access

\begin{abstract}
Introduction: Teenage pregnancy is a common public health problem with global estimates of 16 million teenage births yearly. It is one of the major causes of maternal and neonatal mortality worldwide with the majority of the cases seen in the low and middle-income countries. Cameroon has recorded the highest fertility rate among teenagers in the entire Central African region as of 2017. Notably, there are limited data available on assessing the awareness and prevention of teenage pregnancies among secondary and high school students in Cameroon. Thus, this study aimed at assessing the prevalence and associated factors of teenage pregnancy among secondary and high school students in the Tiko Health District, South West Region, Cameroon. Methods: A cross-sectional descriptive study was conducted whereby data was collected using self-administered questionnaires from 250 systematically sampled participants from five teaching institutions in the Tiko Health District. Data was analysed using the EPI Info software, version 7.0. The study was carried out from the $15^{\text {th }}$ November 2018 to the $20^{\text {th }}$ of May 2019. Results: We had a total of 250 participants. The prevalence of teenage pregnancy was $5.20 \%$ (95\% CI 3.34 - 9.1). A total of $47.20 \%$ (95\% CI: $37.56-53.6$ ) of participants were sexually active. Having multiple partners was a major risk
\end{abstract}


factor for teenage pregnancy (AOR: 3.2, 95\%CI: 1.75 - 4.03, P-value: 0.03). After adjusting for confounders educational level was a risk factor for the awareness of teenage pregnancy (AOR: 0.54, 95\%CI: 0.30 - 0.92, P-value: 0.04). Poor communication skills, social shyness, and lack of knowledge were potential barriers to contraceptive use. Conclusion: Having multiple sexual partners was a risk factor to the prevalence of teenage pregnancy. The majority of adolescents had considerate ideas of teenage pregnancy, its prevention, and its consequences. However, a good number of them lack adequate knowledge of a comprehensive sexuality education. Thus, measures have to be put in place to provide better sex education to adolescents.

\section{Keywords}

Awareness, Adolescents, Prevention, Sexuality, Teenage Pregnancy

\section{Introduction}

Teenage pregnancy is currently a global phenomenon in the world with serious consequences on mothers, babies, and the economy. According to the World Health Organization [WHO] 2018, there were about 16 million yearly cases of teenage pregnancy with an estimated 3 million unsafe abortions [1] [2]. Teenage pregnancies are more likely to suffer from severe obstetric complications accounting for $23 \%$ of the overall burden due to pregnancy and childbirth of women of all ages [3] [4]. When compared to young adults, children born to adolescents are more likely to be born preterm, have low birth weights, and to die in the neonatal or post neonatal period [5] [6].

Teenage pregnancy involved cases were female adolescence between the ages of 13 - 19 becomes pregnant. In Cameroon, about 25\% of 15 - 19-year-old females are already sexually active [1]. The fertility rate in this age group is 127 per 1000 women [7] with $30 \%$ of these births resulting from unplanned pregnancies [8]. A study carried out in the North of Cameroon in 2004 revealed that $27 \%$ of deliveries from 1995 to 2004 were from teenage mothers [9]. One in four deaths among 15 - 19-year-old female pregnancies are of maternal origin [10]. More also, another findings from a study carried out in Makhado municipality, South Africa indicated an increase in awareness of teenagers in that municipality about preventing teenage pregnancy 15 years after a sexual awareness program was initiated in the said locality [11]. Furthermore, a UK based study reported an increase in the knowledge of women about emergency contraception after taking part in an awareness study for 6 months [12]. These all point to a need to access if most adolescents are knowledgeable enough about preventing teenage pregnancy in our setting. Especially as presently information about the awareness of teenage pregnancy among secondary and high school students in Cameroon remains relatively unknown. And notably, teenage pregnancy constituted a major public health problem in Cameroon and denies most teenage mothers of their education. The aim of this study was to provide data on the prevalence, aware- 
ness and prevention of teenage pregnancy among secondary and high school students in the Tiko Health District.

\section{Materials and Methods}

\subsection{Study Area}

This was a cross-sectional descriptive study that was carried out from the $15^{\text {th }}$ November 2018 to the $20^{\text {th }}$ of May 2019. The study took place in the secondary and high schools of the Tiko Health District (THD). THD is a commercial suburb that is mostly occupied by forest land run by the CDC which produces rubber, banana, and palm oil. The THD is situated in the Tiko sub-division within the Fako Division. Fako division is one of the 6 administrative divisions of the South West Region and it has 4 health districts including Tiko. It has a total of 15 learning institutions namely; GTC Tiko, PCHS Tiko, GBHS Tiko, GHS Motombolombo, Sure Foundation, CKC, Starmotec, GBHS Mutengene, KOEL Bilingual College, Cambridge, Spotlight college, OXBICCOL Mutengene, GTHS Ombe, Regina Pacis College and FETCCOL Mutengene. The core quarters in Tiko include; Streets 1 to 7; Motombolombo, Down Beach, New Quarter, P\&T quarters, New Layout, Long Street, Likomba, Golf Club, Mutengene, Ombe. This district is a rural-urban settlement that comprises one of the 18 health districts in the South West Region of the country. It has a surface area of 484 squares $\mathrm{km}$ with a total population estimated in 2010 at 134,647 inhabitants, making a population density of about 278 inhabitants per square kilometre [13]. This study area was chosen mainly because of its high student population.

\subsection{Study Population and Sampling}

A simple random sampling method was used to select the five (5) schools used in the study. This was followed by a stratified random sampling to select participants per school to be used in the study. The inclusion criteria were school teens (both males and females) aged 14 to 19 years attending secondary and high schools at the Tiko Health District. Both males and females were included because it takes both to make pregnancy and recent literature has highlighted the role young men play in teenage pregnancy; as young men have a range of views on their role in pregnancy prevention, from solely their partner's responsibility to shared responsibility. Young men's views and use of contraception depend on relationship status [14]. Middle and late adolescence were chosen because past research has shown that teenage pregnancy is most prevalent among those age categories [15] [16]. Students who never consent to the study and students aged less than 14 years of age and above 19 years of age in the study area were excluded from the study.

Using the Lorenz formula [17] a sample size of 250 was obtained. This population was distributed among the five institutions after a random sampling was done to identify five schools to be used. The sample gotten from each school was based on its student population and calculated using proportionate sampling. 
There was an appropriate representation of both secondary and high schools based on their respective population.

\subsection{Study Procedure and Data Collection}

A self-administered validated questionnaire was used. The questionnaire was divided into 4 main sections [socio-demographic variables, awareness levels, sexual norms and characteristics, and finally risk factors]. Participants completed questionnaires anonymously and voluntarily after being reassured that the data collected would not be used to the detriment of all involved in the research project. Assent was sought from the principal and teachers of the students sampled for the study to abide by the ethical code of conduct for those less than 18 years. Participants were given questionnaires to complete in the classroom at the same time in each school. An average of 3 minutes was allocated for each student involved in the study to complete the questionnaire. The period allocated for this was the lunch-break in order not to disrupt any lectures. The questionnaires were pre-tested in a school (Comprehensive High School) out of the study area to adjust any ambiguity in the questionnaire.

\subsection{Data Management and Analysis}

Data analysis commenced after all questionnaires were collected from the five schools. After all the questionnaires had been answered, the data was imported into EPI info7 software for analysis. Knowledge was assessed by computing the number of correct responses to 20 general knowledge questions on teenage pregnancy and scored. For each correct answer, a score of one (1) was allocated, while the score of zero (0) was allocated for no answer and incorrect answers. The mean score among the participants was calculated and participants who scored less than this mean value were considered to be unaware [inadequately aware] while those scoring the mean value and above were considered to be aware [adequately aware]. All this was based on a similar study on the assessment of Knowledge, Attitudes, and Beliefs of Sexual Transmitted Diseases and HIV among Chinese students [18]. The association analysis of the prevalence and awareness of teenage pregnancy was undertaken by logistic regression. A p-value of less than 0.05 was considered statistically significant.

\section{Results}

\subsection{Socio-Demographic Data among Secondary and High Schools in the THD}

This sample population comprised of 83 males and 167 females. The age of participants ranged from 14 years to 19 years. Approximately half of the participants (50.8\%) belonged to the $18-19$ age categories. There were a total of 115 and 135 secondary and high school participants respectively. Female participants constituted a majority of $66.8 \%$. The rest of the breakdown of demographic data can be seen in Table 1. 
Table 1. Socio-demographic data of the study population.

\begin{tabular}{cc}
\hline Variables & No (\%) \\
\hline Age (years) & $19(7.6)$ \\
$14-15$ yrs & $104(41.6)$ \\
$16-17$ yrs & $127(50.8)$ \\
$18-19$ yrs & \\
Educational level & $115(46.0)$ \\
Secondary School & $135(54.0)$ \\
High School & \\
Gender & $83(33.2)$ \\
Male & $167(66.8)$ \\
Female & \\
Marital status & \\
Single & $250(100)$ \\
Married & $00(00)$ \\
No $=$ Frequency & \\
\hline
\end{tabular}

\subsection{Prevalence of Teenage Pregnancy among Secondary and High School Students in the THD}

The overall prevalence of teenage pregnancy was revealed to be $5.20 \%$ (95\%CI: 3.34 - 9.1) (Figure 1).

\subsubsection{Sexual Characteristics of Teenage Pregnancy among Secondary and High School Students}

The result also showed that a total of $47.20 \%$ (95\%CI: 37.56 - 53.6) of participants were sexually active (Figure 2). The results further revealed that $51.08 \%$ (95\% CI: 47.56 - 55.6) of 16 - 19 years old adolescents were sexually active.

\subsubsection{Factors Associated with Teenage Pregnancy among Secondary and} High School Students in the THD

Multiple partners was the only factor that had a great influence with statistical significance on teenage pregnancy in secondary and high school students in Tiko Health District (95\% CI: 1.23 - 13.0, P-value: 0.02) as those with multiple partners were 4.0 times more likely to have teenage pregnancy compared to those without (O.R: 4.0). After adjusting for confounders, again only multiple partners had an association (AOR: 3.2, CI: 1.75 - 4.03, P-value 0.03) as shown in Table 2.

\subsection{Awareness of Teenage Pregnancy among the Secondary and High School Students in the THD}

The findings revealed that $70.40 \%$ (CI: 67.56 - 74.6) of participants were aware of teenage pregnancy, its consequences, and prevention (Figure 3 ). 


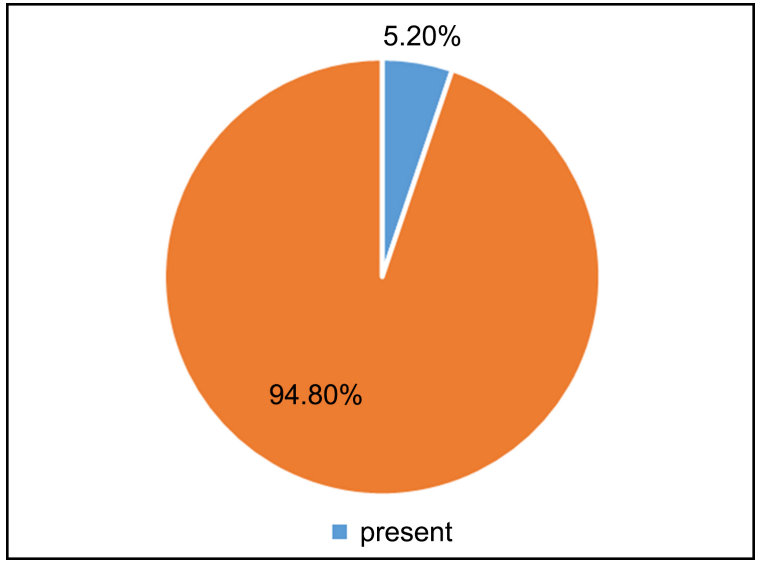

Figure 1. Prevalence of teenage pregnancy among secondary and high school students in the THD.

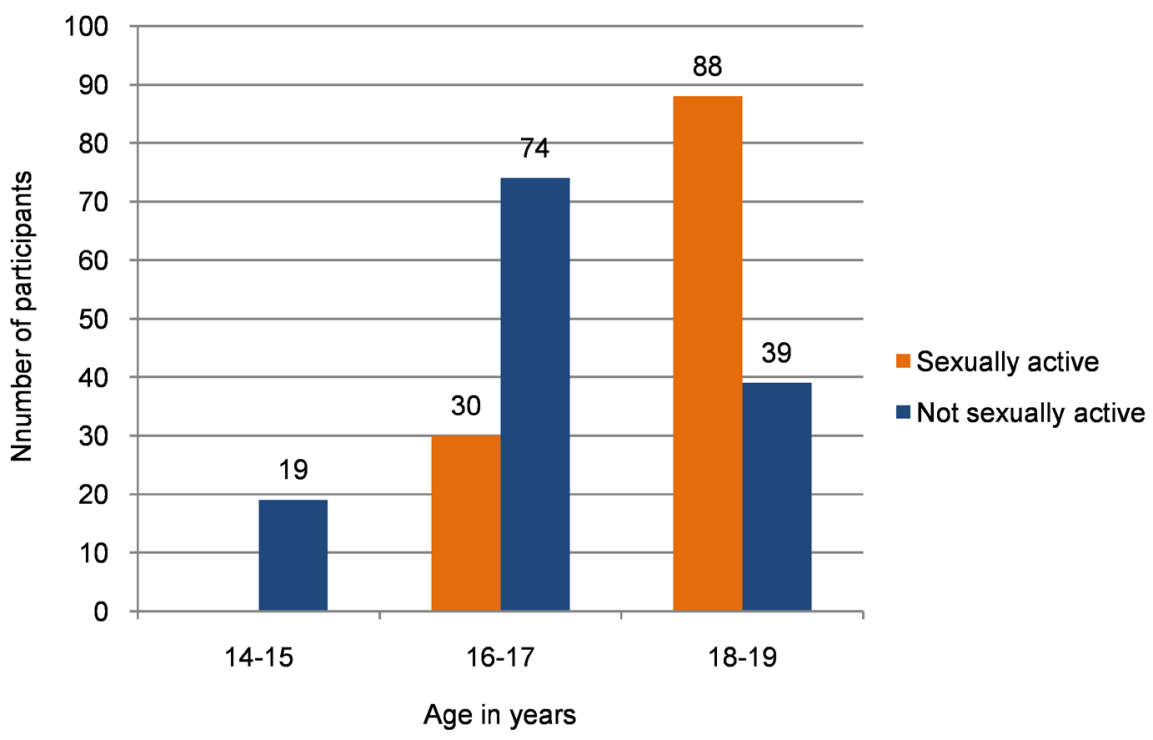

Figure 2. Age distribution of sexual activity among secondary and high school students in the THD.

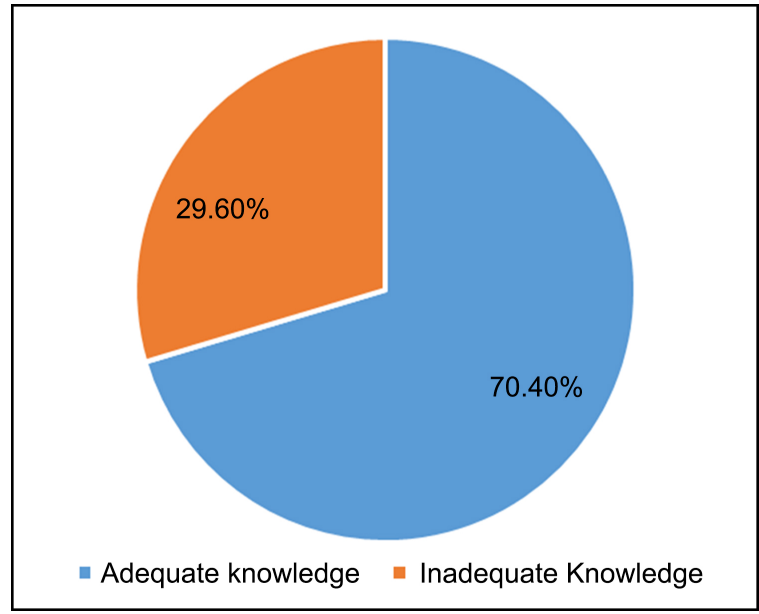

Figure 3. Awareness of teenage pregnancy. 
Table 2. Risk factors associated with teenage pregnancy among secondary and high school students in the THD.

\begin{tabular}{|c|c|c|c|c|c|}
\hline Variable & COR $(95 \% \mathrm{CI})$ & p-value & AOR & $95 \% \mathrm{CI}$ & p-value \\
\hline \multicolumn{6}{|l|}{ Educational level } \\
\hline Secondary school & 1 & & & & \\
\hline High school & $0.51(0.16-1.62)$ & 0.26 & 0.72 & $0.41-1.63$ & 0.23 \\
\hline \multicolumn{6}{|l|}{ Awareness of TP } \\
\hline Unaware & 1 & & & & \\
\hline Aware & $0.47(0.15-1.45)$ & 0.19 & 1.52 & $0.87-3.02$ & 0.31 \\
\hline \multicolumn{6}{|l|}{ Dating older people } \\
\hline No & 1 & & & & \\
\hline Yes & $2.7(0.89-8.58)$ & 0.08 & 1.55 & $0.84-2.03$ & 0.12 \\
\hline \multicolumn{6}{|l|}{ Sexually active friends } \\
\hline No & 1 & & & & \\
\hline Yes & $1.14(0.34-3.84)$ & 0.82 & 1.03 & $0.78-2.17$ & 0.65 \\
\hline \multicolumn{6}{|l|}{ Watching pornographic movies } \\
\hline No & 1 & & & & \\
\hline Yes & $2.69(0.58-12.47)$ & 0.20 & 1.41 & $0.74-2.37$ & 0.55 \\
\hline \multicolumn{6}{|l|}{ Can live the house at anytime } \\
\hline No & 1 & & & & \\
\hline Yes & $2.33(0.68-7.95)$ & 0.18 & 1.02 & $0.68-2.16$ & 0.12 \\
\hline \multicolumn{6}{|l|}{ Sexually abused in the past } \\
\hline No & 1 & & & & \\
\hline Yes & $1.58(0.47-5.35)$ & 0.46 & 1.03 & $0.76-2.07$ & 0.13 \\
\hline \multicolumn{6}{|c|}{ Family history of teenage pregnancy } \\
\hline No & 1 & & & & \\
\hline Yes & $0.82(0.24-2.76)$ & 0.76 & 1.01 & $0.64-2.01$ & 0.36 \\
\hline \multicolumn{6}{|l|}{ Multiple partners } \\
\hline No & 1 & & 1 & & \\
\hline Yes & $4.0(1.23-13.0)$ & 0.02 & 3.2 & $1.75-4.03$ & 0.03 \\
\hline \multicolumn{6}{|l|}{ Age category } \\
\hline $16-17 \mathrm{yrs}$ & 1 & & & & \\
\hline $14-15 \mathrm{yrs}$ & $0.00(0.00-1.0)$ & 0.98 & 1.73 & $0.91-3.20$ & 0.39 \\
\hline $18-19$ yrs & $2.88(0.77-10.7)$ & 0.12 & 0.57 & $0.3-1.07$ & 0.41 \\
\hline \multicolumn{6}{|l|}{ Sexual norms } \\
\hline Doesn't accept sex relations & 1 & & & & \\
\hline Accepts active sex relations & $1.88(0.56-6.27)$ & 0.30 & 0.81 & $0.41-1.64$ & 0.9 \\
\hline \multicolumn{6}{|c|}{$\begin{array}{l}\text { Source of knowledge on prevention } \\
\text { of teenage pregnancy }\end{array}$} \\
\hline School & 1 & & & & \\
\hline Others & $0.95(0.30-3.02)$ & 0.94 & 0.36 & $0.26-1.04$ & 0.83 \\
\hline
\end{tabular}


Factors Associated with Awareness of Teenage Pregnancy among Secondary and High School Students in the THD

Among the factors that were tested to using logistic regression for any influence on awareness of teenage pregnancy, just Educational level (high school) had a significant association with adequate knowledge on teenage pregnancy as those in high school were 2.0 times more likely to have adequate knowledge on teenage pregnancy as a whole compared to those in secondary schools (P: 0.01, O.R: 2.0). After adjusting for confounders just again, educational level showed an association (AOR: 0.54, CI: 0.30 - 0.92; P-value 0.04). The rest of the associations are shown in (Table 3 ).

\subsection{Most Commonly Used Contraceptive Method in Secondary and High Schools in the THD}

The most commonly used contraceptive methods among secondary and high school students was the male condom (49.1\% and $49.2 \%$ respectively) (Figure 4). Coitus interruptus $(12.7 \%$ and $15.9 \%$ of secondary and high school students respectively) was the next most commonly used with the least utilized being contraceptive pills (3.6\% and 3.1\%) of secondary and high school students respectively. A total of $34.5 \%$ and $31.7 \%$ of secondary and high school students respectively don't use any method of birth control.

\section{Barriers to Contraception among Secondary and High Schools in the THD}

Feeling embarrassed while purchasing condoms, the notion that condoms reduce sexual pleasure and the notion that birth control concerns only women were the 3 most prevailing barriers identified. The rest of the breakdown of responses can be seen in Figure 5.

Table 3. Factors associated with awareness of teenage pregnancy among secondary and high school students in the THD.

\begin{tabular}{cccccc}
\hline Variable & Bivariate analysis & \multicolumn{4}{c}{ Multivariate analysis } \\
\cline { 2 - 6 } & COR $(95 \%$ C.I $)$ & $p$-value & AOR & $95 \%$ CI & P-Value \\
\hline $\begin{array}{c}\text { Educational level } \\
\text { Secondary School }\end{array}$ & 1 & 1 & 1 & 1 & \\
High school & $2.0(1.15-3.48)$ & 0.01 & 0.54 & $0.30-0.92$ & 0.04 \\
$\quad$ Gender & & & & & \\
Male & 1 & & 1 & & \\
Females & $1.58(0.89-2.78)$ & 0.11 & 1.62 & $0.68-2.07$ & 0.96 \\
Institution type & & & & & \\
Government & 1 & & 1 & & \\
Private & $1.46(0.84-2.52)$ & 0.17 & 0.71 & $0.40-1.62$ & 0.85 \\
Age category & & & & & \\
16 - 17 yrs & 1 & & 1 & & \\
14 - 15 yrs & $1.13(0.38-3.43)$ & 0.82 & 1.65 & $0.94-2.13$ & 0.83 \\
18 - 19 yrs & $0.91(0.51-9.61)$ & 0.76 & 1.42 & $0.75-2.38$ & 0.71 \\
\hline
\end{tabular}




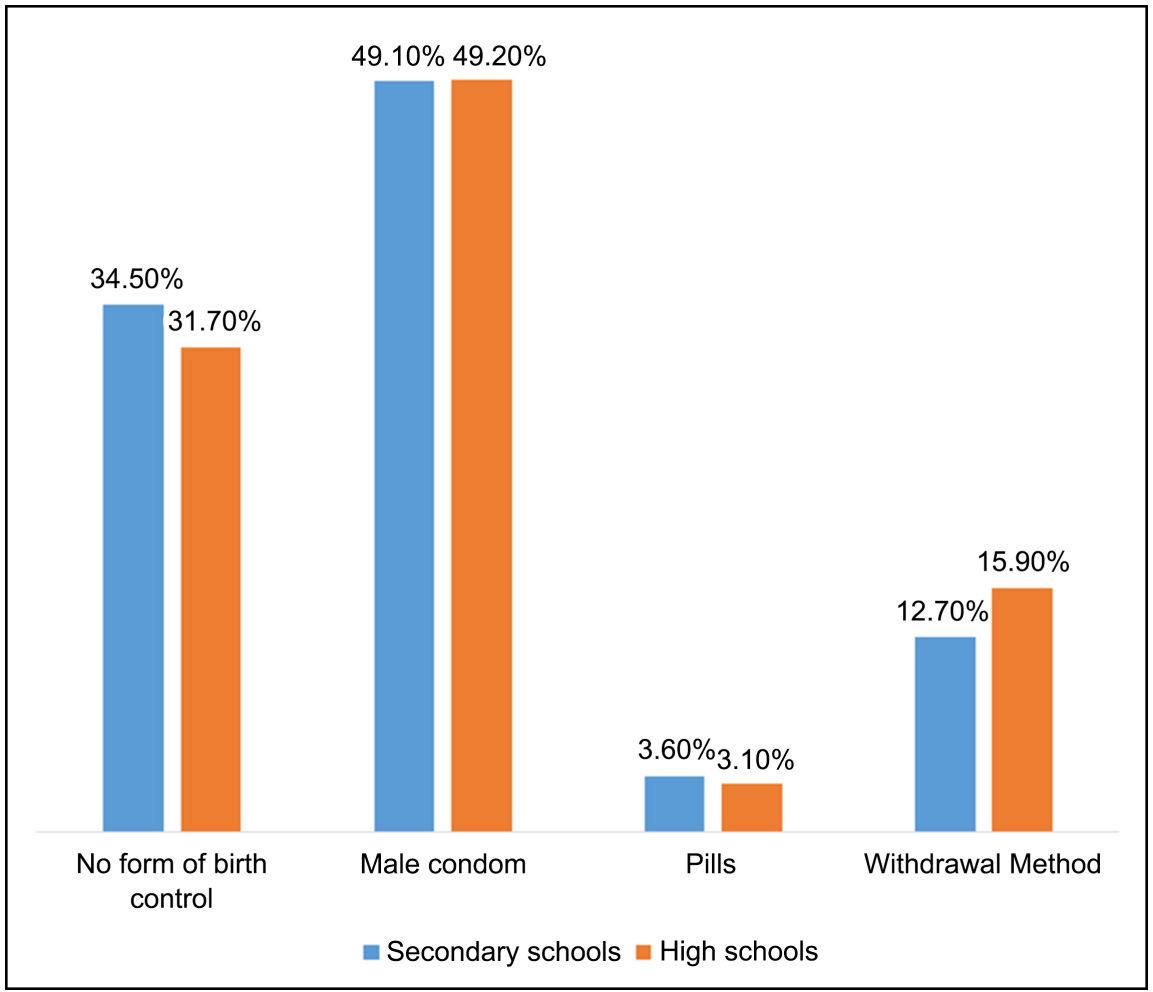

Figure 4. Contraceptive usage distribution.

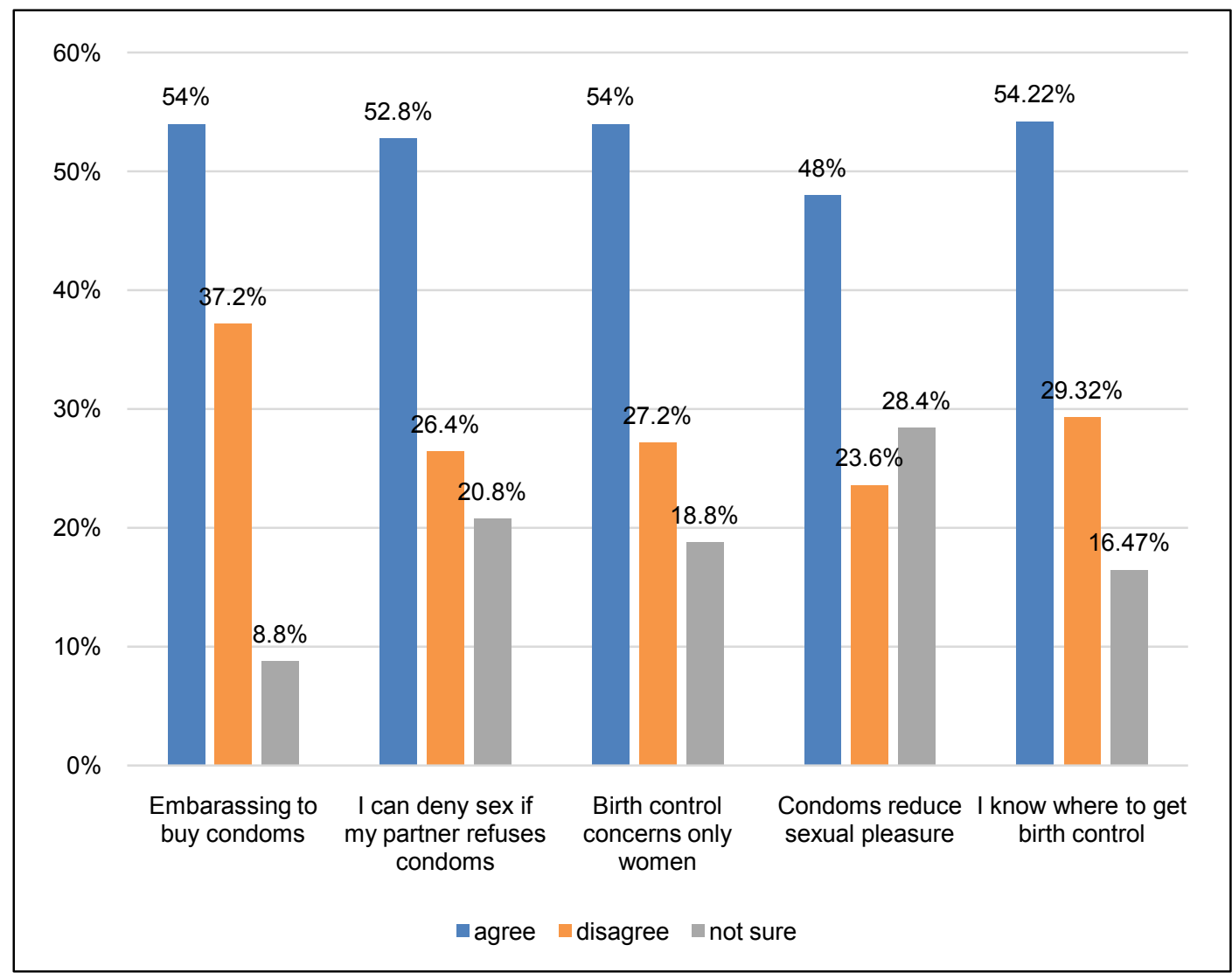

Figure 5. Breakdown of potential barriers to contraceptive use. 


\section{Discussion}

Our study came into conception due to the lack of adequate studies on the awareness of teenage pregnancy among secondary and high school students in Cameroon, despite its alarming rate, and as it is an important indicator of maternal and neonatal morbidity and mortality. Our study was meant to determine the prevalence, and associated factors of teenage pregnancy among secondary and high school students. The overall prevalence of teenage pregnancy was found to be $5.20 \%$. This is lower than the values reported by a study carried out by the University teaching hospital of Yaoundé of 12\% [19], the 13.3\% reported by a 2015 study at the Buea health district [20], the $11 \%$ reported by a 2016 study in South Africa [21], and also lower than the $60.5 \%$ reported by a 2018 study in Cameroon [22]. A possible reason for this disparity is the fact that our research was carried out in schools and a majority of the teenage mothers had dropped out of school. Hence a majority of them could not participate in the study. Also, with the research being socially sensitive, this might have prompted the participants to be biased and give socially desirable answers. Further calculations revealed that $44.44 \%$ of females aged $16-19$ years are sexually active. This is a lot higher than the $25.00 \%$ estimate of 2017 seen in a Bafoussam study in Cameroon [1]. A probable reason for this is an increase in the amount of free time available to adolescents with a concomitant increase in the availability of android phones.

The findings revealed that the majority of participants (70.40\%) were aware of teenage pregnancy. This was a lot similar to the $68 \%$ and $68.95 \%$ average seen in a 2016 South African study [11] and 2018 Cameroonian study [22] respectively. Higher levels of education had a significant association with TP as high school participants are 2 times more likely to be aware of TP than secondary school participants. This was similar to the findings of studies carried out in Botswana [23], Tanzania [24], and Zambia [25] that identified education and socioeconomic status as consistent determinants of awareness of teenage pregnancy.

However, no statistical significance was seen between awareness levels and teenage pregnancy as reported by a 2009 study carried out in South Africa [26]. A probable reason for this explanation could be the bias of the participants while answering the questionnaires since the topic is socially sensitive. Hence many might not want to admit to have been pregnant or gotten a girl pregnant. Finally many of the participants that have experienced a teen pregnancy which could have influenced the results had dropped out of school and since this was a school-based study, they couldn't participate.

The results revealed that among sexually active individuals, $25.42 \%$ of participants never carried out contraception. This is a lot lower than the $46.42 \%$ reported by a 2018 study in Cameroon [22]. A probable reason for this disparity is because our study focused on both male and female adolescents but this other study focused mainly on female adolescents.

The most commonly used contraceptive at last intercourse was found to be the male condom [49.15\%]. This is consistent with the findings of a 2017 study 
in Cameroon which reported male condom use as the most prevalent contraceptive being used among adolescents [1].

Some of the barriers to contraceptive use identified such as Social stigmatization and lack of knowledge on where to acquire and how to use them were similar findings in a 2006 study carried out in Nigeria [27].

The results revealed that the participants of this study were exposed to a variety of risk factors. However, only one risk factor was found to be associated with teenage pregnancy in this study. It was discovered that the presence of multiple partners had a significant influence on teenage pregnancy in secondary and high school students in the Tiko Health District (p: 0.02) as those with multiple partners were 4.0 times more likely to have a teenage pregnancy compared to those without (O.R: 4.0, AOR: 3.2). This corresponds with the findings of a 2016 study in South Africa [21].

\section{Study Limitations}

1) The bias of students was difficult to eliminate as the research topic is sensitive. This might have prompted the majority of the participants to be dishonest and give socially desired answers.

2) Given that the sample size was small, the data gotten might not reflect the view of the entire population. Especially as the study was school-based and a majority of teenage mothers and those who might have experienced teen pregnancy might have dropped out of school.

\section{Conclusions}

The overall prevalence of teenage pregnancy in both secondary and high school was $5.20 \%$. The prevalence within the secondary and high school students was $7.0 \%$ and $3.7 \%$ respectively and there was no statistically significant difference in the prevalence between both groups. Overall $70.4 \%$ of teenagers in both secondary and high school had adequate knowledge of teenage pregnancy. Inadequate knowledge was statistically linked to engaging in sexual activity. $62.6 \%$ and $77 \%$ of secondary and high school students respectively in the Tiko Health District had adequate knowledge of teenage pregnancy. Higher education levels had a significant influence on awareness levels but had little influence on teenage pregnancy.

The most commonly used contraceptive method among secondary and high schools was the male condom. Social shyness and stigmatization, poor communication skills and lack of knowledge on contraceptives and where to get them were potential barriers to contraceptive use. The major risk factor that exposes teenagers in the Tiko Health District significantly to teenage pregnancy was the presence of multiple dating partners.

\section{Ethical Consideration}

Ethical approval was obtained from the Institutional Review Board of the Faculty 
of Health Sciences University of Buea. Authorizations were sort from all the principals of the schools used in the study. Furthermore, all participants were informed of the aim and the procedures to be used in the study. Participants signed a consent or assent form, and were informed of their right to back-out of the study at any time and that no personal identifying information would be collected from them.

\section{Availability of Data and Materials}

The dataset and materials of the study are available through the author ESEG and will be made accessible on request at the email: elongaterre@gmail.com.

\section{Acknowledgements}

We are grateful to the Delegate of Public Health of the South West Region, Faculty of Health Sciences of the University of Buea, and the principals, staff, and students of GBHS Tiko, GHS Motombolombo, Sure Foundation, Starmotec and PCHS Tiko for their cooperation and support.

\section{Authors' Contributions}

ESEG participated in the conception, literature review, design of the study, data analysis and management. HEEG participated in conception, design, and review. MI participated in conception, literature data collection, data management, data analysis, interpretation, and revising the manuscript for publication. FSK participated in drafting, and revising the manuscript for publication. MLNL participated in literature review, design and data management. NDS participated in design and revising the manuscript for publication. CBM participated in design, data collection and management. NCC participated in data collection and management. MNV participated in conception, study design, and review. All authors read and approved the final copy.

\section{Conflicts of Interest}

The authors declared no conflicts of interest regarding the publication of this paper.

\section{References}

[1] Ambe, C.G. (2017) Risk Factors for Adolescent Pregnancy and HIV in Bafoussam, Cameroon. Doctoral Dissertation, School of Public Health, University of the Western Cape, Bellville. https://hdl.handle.net/11394/5961

[2] World Health Organization (2012) Adolescent Pregnancy: Fact Sheet 364. WHO, Geneva. http://www.who.int/mediacentre/factsheets/fs364/en/

[3] World Health Organization (2011) WHO Guidelines on Preventing Early Pregnancy and Poor Reproductive Health Outcomes among Adolescents in Developing Countries. World Health Organization, Geneva. http://whqlibdoc.who.int/publications/2011/9789241502214_eng.pdf

[4] World Health Organization (2012) Early Marriages, Adolescent and Young Preg- 
nancies: Report by the Secretariat. Sixty-Fifth World Health Assembly: Provisional Agenda Item 13.4. World Health Organization, Geneva. http://apps.who.int/gb/ebwha/pdf_files/WHA65/A65_13-en.pdf

[5] Chen, X.K., Wen, S.W., Fleming, N., Demissie, K., Rhoads, G.G. and Walker, M. (2007) Teenage Pregnancy and Adverse Birth Outcomes: A Large Population Based Retrospective Cohort Study. International Journal of Epidemiology, 36, 368-373. https://doi.org/10.1093/ije/dyl284

[6] Chen, X.K., Wen, S.W., Fleming, N., Yang, Q. and Walker, M.C. (2008) Increased Risks of Neonatal and Post-Neonatal Mortality Associated with Teenage Pregnancy Had Different Explanations. Journal of Clinical Epidemiology, 61, 688-694. https://doi.org/10.1016/j.jclinepi.2007.08.009

[7] National Institute of Statistics (INS) and ICF International (2012) Cameroon Demographic and Health Survey and Multiple Indicators (EDS-MICS) .2011. INS/ Cameroon and ICF International, Calverton, Maryland, USA. http://dhsprogram.com/pubs/pdf/FR260/FR260.pdf

[8] Fomo, M.A. and Ngono, G. (2012) Preferences for Fertility. In: National Institute of Statistics (INS) and ICF International, Eds., Demographic and Health Survey and Multiple Indicators of Cameroon 2011, INS and ICF International, Maryland, 89-98.

[9] Tebeu, P.M., Tantchou, J., Obama Abena, M.T., Mevoula Onala, D. and Leke, R.J. (2006) Delivery Outcome of Adolescents in Far North Cameroon. Revue Médicale de Liège, 66, 124-127.

[10] Libite, P.R. and Barrère, B. (2012) Adult Mortality and Maternal Mortality. In: National Institute of Statistics (INS) and ICF International, Eds., Demographic and Health Survey and Multiple Indicators of Cameroon 2011, INS and ICF International, Maryland, 219-224

[11] Maxwell, G.M., RadzilaniMakatu, M. and Takalani, J.F. (2016) Awareness of prevention of Teenage Pregnancy among Secondary School Learners in Makhado Municipality. African Journal of Primary Health Care \& Family Medicine, 8, 1-5. https://doi.org/10.4102/phcfm.v8i2.967

[12] Smith, L.F. and Whitfield, M.J. (1995) Women's Knowledge of Taking Oral Contraceptive Pills Correctly and of Emergency Contraception: Effect of Providing Information Leaflets in General Practice. British Journal of General Practice, 45, 409-414.

[13] Tambe, A.B., Nzefa, L.D. and Nicoline, N.A. (2015) Childhood Diarrhea Determinants in Sub-Saharan Africa: A Cross Sectional Study of Tiko-Cameroon. Challenges, 6, 229-243. https://doi.org/10.3390/challe6020229

[14] Vargas, G., Borus, J. and Charlton, B.M. (2017) Teenage Pregnancy Prevention: The Role of Young Men. Current Opinion in Pediatrics, 29, 393-398.

[15] Blum, R.W. and Gates, W.H. (2015) Girlhood, Not Motherhood: Preventing Adolescent Pregnancy. United Nations Population Fund (UNFPA).

https://www.unfpa.org/sites/default/files/pub-pdf/Girlhood_not_motherhood_final _web.pdf

[16] Neal, S., Matthews, Z. and Frost, M. (2012) Childbearing in Adolescents Aged 12-15 Years in Low Resource Countries: A Neglected Issue. New Estimates from Demographic and Household Surveys in 42 Countries. Acta Obstetricia et Gynecologica Scandinavica, 91, 1114-1118. https://doi.org/10.1111/j.1600-0412.2012.01467.x

[17] Charan, J. and Biswas, J. (2013) How to Calculate Sample Size for Different Study Designs in Medical Research. Indian Journal of Psychological Medicine, 35, 121-126. 
[18] Tan, X.D., Pan, J.J., Zhou, D., Wang, C.H. and Xie, C.J. (2007) HIV/AIDS Knowledge, Attitudes and Behaviors Assessment of Chinese Students: A Questionnaire Study. International Journal of Environmental Research and Public Health, 4, 248-253. https://doi.org/10.3390/ijerph2007030009

[19] Fouelifack, F.Y., Tameh, T.Y., Mbong, E.N., Nana, P.N., Fouedjio, J.H., Fouogue, J.T. and Mbu, R.E. (2014) Outcome of Deliveries among Adolescent Girls at the Yaoundé Central Hospital. BMC Pregnancy Childbirth, 14, Article No. 102.

[20] Egbe, T.O., Omeichu, A., Halle-Ekane, G.E., Tchente, C.N., Egbe, E.-N. and Oury, J.-F. (2015) Prevalence and Outcome of Teenage Hospital Births at the Buea Health District, South West Region, Cameroon. Reproductive Health, 12, Article No. 118.

[21] Jonas, K., Crutzen, R., Van den Borne, B., Sewpaul, R. and Reddy, P. (2016) Teenage Pregnancy Rates and Associations with Other Health Risk Behaviours: A Three-Wave Cross-Sectional Study among South African School-Going Adolescents. Reproductive Health, 13, Article No. 50.

[22] Donatus, L., Sama, D.J., Tsoka-Gwegweni, J.M. and Cumber, S.N. (2018) Factors Associated with Adolescent School Girl's Pregnancy in Kumbo East Health District North West Region Cameroon. Pan African Medical Journal, 31, Article 138.

[23] Molosiwa, S. and Moswela, B. (2012) Girl-Pupil Dropout in Secondary Schools in Botswana: Influencing Factors, Prevalence and Consequences. International Journal of Business and Social Science, 3, 265-271.

[24] Nyakubega, P. (2010) Factors Associated with Adolescent Pregnancies among Secondary School Students. A Study from Tanga-Tanzania. Dar Es Salaam Medical Students' Journal, 16, 31-34.

[25] Nwogwugwu, N.C. (2013) Socio-Demographic Determinants of Adolescent Fertility in Zambia. http://wiredspace.wits.ac.za/handle/10539/12639

[26] Panday, S., Makiwane, M., Ranchod, C. and Letsoala, T. (2009) Teenage Pregnancy in South Africa: With a Specific Focus on School-Going Learners. Commission by UNICEF, July. http://hdl.handle.net/20.500.11910/4711

[27] Salako, A.A., Iyaniwura, C.A., Jeminusi, O.A. and Sofowora, R. (2006) Sexual Behaviour, Contraception and Fertility among In-School Adolescents in Ikenne Local Government, South-Western Nigeria. Nigerian Journal of Clinical Practice, 9, 26-36. 


\section{Abbreviations}

CI: Confidence Interval,

CSE: Comprehensive Sexuality Education, DHS: Demographic and Health Surveys, COR: Corrected Odds Ratio, HIV: Human Immunodeficiency Virus, NGO: Non-Governmental Organization, STI: Sexually Transmitted Infection,

TP: Teenage Pregnancy, THD: Tiko Health District, VVF: Vesico-Vaginal Fistula, WHO: World Health Organizations, ESEG: Ebanja Silva Elonge Gabrie, HEEG: Halle-Ekane Eddie Gregorie, MI: Mohamed Isah, FSW: Frankline Sevidzem Wirsiy, MLNL: Max Langmia Nambeke Lebage, NDS: Ndzeshang Dympna Siysila, CBM: Catherine Binye Musi,

NCC: Ngong Clovis Chia, MNV: Mbome Njie Victor. 